\title{
Occurrence and diversity of microalgae in phytoplankton collected from freshwater community ponds of Hooghly District, West Bengal, India
}

\author{
Papiya Halder $^{1}$, Manojit Debnath ${ }^{2 *}$, Samit Ray ${ }^{1}$ \\ ${ }^{1}$ Department of Botany, Visva-Bharati, Santiniketan 731235, West Bengal, India \\ ${ }^{2}$ Genetics and Molecular Biology Division, CSIR-National Botanical Research Institute. Lucknow, Uttar Pradesh 226001, India
}

\section{Article history}

Received: 17 September 2018 Accepted: 29 December 2018

Published: 09 January 2019

\section{Editor}

Dr Nishikant Wase

University of Nebraska-Lincoln USA

\section{Publisher}

Horizon e-Publishing Group

\section{*Correspondence \\ Manojit Debnath \\ $凶$ mandeb@rediffmail.com}

\begin{abstract}
A study on diversity, seasonal occurrence, distribution percentage of microalgal taxa and physicochemical parameters of five community ponds, located in Chinsurah town, Hooghly district of West Bengal, has been carried out. Correlation between occurrence of microalgal genera and some parameters of environment, physico-chemical nature of natural water bodies were explored by Canonical Correspondence Analysis (CCA). Diversity indices have been calculated using PAST software program. A total of 23 microalgal taxa belonging to four algal classes were recorded and the study indicated that the microalgal diversity vary with variation in physico-chemical parameters of water and light intensity. Out of these genera, occurrence of Chodatella sp. in late summer and Tetrallantos sp. and Synechocystis sp. in winter season were specific. In CCA, multiple variables (dissolved oxygen, water temperature, electrical conductivity, pH, light intensity and inorganic phosphorous) played a significant role in occurrence of microalgal taxa. Observation concluded that the Chlorophycean members were dominant throughout the study period and the Shannon-Wiener diversity index was highest for a site with large number of Chlorophycean member. This study will help in future to assess water quality.
\end{abstract}

Keywords: Microalgae; Community pond; Seasonal occurrence

\begin{abstract}
Abbreviations
L.I, Light intensity; W.T, Water temperature; pH, Water pH; E.C, Electrical conductivity; D.o, Dissolved oxygen; I.P, Inorganic phosphorous; Sce., Scenedesmus sp.; Sel., Selenastrum sp.; Chl., Chlorococcum sp.; Tet., Tetraedron sp.; Tetr., Tetrallantos sp.; Sch., Schroederia sp.; Tetra., Tetrastrum sp.; Act., Actinochloris sp.; Cos., Cosmaium sp.; Clo., Closterium sp.; Cru., Crucigenia sp.; Coe., Coelastrum sp.; Chlo., Chlorella sp.; Ooc., Oocystis sp.; Ped., Pediastrum sp.; Cho., Chodatella sp.; Ank., Ankistrodesmus sp.; Syn., Synechocystis sp.; Mer., Merismopedia sp.; Nav., Navicula sp.; Pin., Pinnularia sp.; Eug., Euglena sp.; Pha., Phacus sp.
\end{abstract}

\section{Citation}

Halder P, Debnath M, Ray S. Occurrence and diversity of microalgae in phytoplankton collected from freshwater community ponds of Hooghly District, West Bengal, India. Plant Science Today 2019;6(1):816. https://dx.doi.org/10.14719/pst.2019.6.1.426

Copyright: ( $)$ Halder et al. (2019). This is an open-access article distributed under the terms of the Creative Commons Attribution License, which permits unrestricted use, distribution, and reproduction in any medium, provided the original author and source are credited (https://creativecommons.org/licenses/by/4.0/).

Indexing: Plant Science Today is covered by Scopus, CAS, AGRIS, CABI, Google Scholar, etc. Full list at http://www.plantsciencetoday.online

These organisms have a critical role in primary production, nutrient cycling and food web in the aquatic ecosystem (1). Apart from that, microalgae in the aquatic ecosystems are indicators of changes 
that take place due to anthropogenic activities and environmental pollution. The diversity of these microalgae occurring as phytoplankton is influenced by various biotic and abiotic factors. Considering these aspects extensive studies have been carried out in India on the microalgae occurring as phytoplankton. These include seasonal distribution (2-4), diversity of fresh water algae (4,5-14) physico-chemical parameters of aquatic system $(3,4,15-17)$ and algal blooms $(4,18)$. These works have been carried out with respect to both lotic and lentic ecosystems.

Studies concerning role of microalgae in water quality monitoring shows that changes in taxon diversity and composition indicate not only changes in physical and chemical variables of water, but also changes in biotic interactions (19). Ecological studies include seasonality of microalgal occurrence, natural variation of physico-chemical factors in water bodies and the relationship between occurrence and diversity of algal taxa and environmental factors (19,20-22). To cope up with the changes, microalgal taxa have developed morphological and physiological adaptive strategies for surviving in different environments $(19,23,24)$. Defined functional groups of microalgae with defined morphological and physiological traits were also studied in a given environment (19). It is also important to mention here that fresh water ecosystems are associated with human activity in the rural India. These are an important source of water for daily use and sustaining the livelihoods. The present study has been undertaken in some fresh water bodies, not studied earlier, in a town Chinsurah of district Hooghly of state of West Bengal. These fresh water bodies are located in the middle of the town and exposed to various pollutants. The prime objective of this study, on the occurrence and diversity of the microalgal component and their correlation with physico-chemical parameters, was to form a data bank of species diversity and growth condition for future prospect of using them in pollution monitoring.

\section{Materials and Methods}

(a) Study area: The study area is located in Chinsurah town of Hooghly district, West Bengal, India. Five fresh water ponds were selected in this study area and their latitude and longitude were obtained from GPS data (Table 1). The five sites were marked as Site I, Site II, Site III, Site IV, Site V. The ponds were almost of the same size and located in area inhabited by people. They are used for household purposes and they received effluent through the drainage system (Photo plate 1).

(b) A random sampling method was used for the collection of samples from the selected sites over two different seasons- Late Summer and Winter. The samples were collected using a sampling bottle.

(c) After collection, three aliquots of sample each of $12 \mathrm{ml}$ centrifuged and pellets were collected for species diversity study. Voucher sample was preserved in $4 \%$ formaldehyde for qualitative and quantitative analysis in laboratory. Microalgal species were identified on the basis of morphological features following published works (25-28). 10\% glycerine was used as mounting material for microscopic study.

(d) The organisms were photographed using Olympus CH20i.

(e) Shannon-Wiener index of diversity $\left[\mathrm{H}^{\prime}\left(\log _{\mathrm{e}}\right)\right]$, Simpson's dominance index ( $\mathrm{D}_{\text {sImp }}$ ), Pielou's evenness index (J/), and Margalef 's richness index ( $D_{\text {MARG) }}$ were calculated using PAST statistical software version 2.07 to show microalgal community structure.

(f) Temperature was noted by Eurolab ST9869B multi-thermometer, light intensity by LT Lutron LX-101 lux-meter, $\mathrm{pH}$ by Eutech instruments $\mathrm{pH}$ 700, for Electrical conductivity, Systronics conductivity meter 304 was used.

(g) For Inorganic phosphorous estimation, 50ml of water sample were taken and added $2 \mathrm{ml}$ of ammonium molybdate followed by 5 drops of stannous chloride solution. After $5 \mathrm{~min}$ but before $12 \mathrm{~min}$ of the addition of the last reagent the absorbance was measured at $690 \mathrm{~nm}$ by UV-Visible spectrophotometer (UV-1800 Shimadzu).

(h) Dissolved oxygen was calculated by Winkler's Iodometric method.

(i) Canonical Correspondence Analysis: Canonical Correspondence Analysis (CANOCO version 4.5; terBraak, 1986) was used to understand the correlation between physicochemical parameters of fresh water and fresh water microalgal component in late summer and winter seasons. Biplot scores of the environmental parameters were noted. CCA ordination was tested

Table 1. List of sampling sites in Chinsurah, Hooghly the state of West Bengal India

\begin{tabular}{|c|c|c|}
\hline Name of sampling stations & Name of the location & Latitude and longitude \\
\hline Site I & Bonokalitala in Chinsurah,Hooghly & $\mathrm{N}-22^{\circ} 53.141^{\prime} \quad \mathrm{E}-88^{\circ} 23.231^{\prime}$ \\
\hline Site II & Bonokalitala in Chinsurah,Hooghly & $\mathrm{N}-22^{\circ} 53.171^{\prime} \mathrm{E}-88^{\circ} 23.142^{\prime}$ \\
\hline Site III & Dharampur in Chinsurah,Hooghly & $\mathrm{N}-22^{\circ} 53.434^{\prime} \quad \mathrm{E}-88^{\circ} 23.238^{\prime}$ \\
\hline Site IV & Bonokalitala in Chinsurah,Hooghly & N-22 $53.178^{\prime}$ E- $88^{\circ} 23.142^{\prime}$ \\
\hline Site V & Khadinamore in Chinsurah,Hooghly & 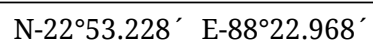 \\
\hline
\end{tabular}


Table 2. Diversity of microalgal component in sampling sites in Chinsurah in Hooghly district of West Bengal. (+: Present; -: absent) (L.S: Late summer, W: Winter)

Sl. No. Phytoplankton

Sampling Stations Pond

S1. No. Phytoplankton

\begin{tabular}{|c|c|}
\hline 1. & Scenedesmus sp. \\
\hline 2. & Selenastrum sp. \\
\hline 3. & Chlorococcum sp. \\
\hline 4. & Tetraedron sp. \\
\hline 5. & Tetrallantos sp. \\
\hline 6. & Schroederia sp. \\
\hline 7. & Tetrastrum sp. \\
\hline 8. & Actinochloris sp. \\
\hline 9. & Closterium sp. \\
\hline 10. & Cosmarium sp. \\
\hline 11. & Crucigenia sp. \\
\hline 12. & Coelastrum sp. \\
\hline 13. & Chlorella sp. \\
\hline 14. & Oocystis sp. \\
\hline 15. & Pediastrum sp. \\
\hline 16. & Chodatella sp. \\
\hline 17. & Ankistrodesmus sp. \\
\hline 18. & Synechocystis sp. \\
\hline 19. & Merismopedia sp. \\
\hline 20. & Navicula sp. \\
\hline 21. & Pinnularia sp. \\
\hline 22. & Euglena sp. \\
\hline 23. & Phacus sp. \\
\hline
\end{tabular}

Total Microalgal component $=23$

Table 3. Physico-chemical parameters in late summer (L.S) and winter (W) of sampling sites

\begin{tabular}{|c|c|c|c|c|c|c|c|c|c|c|}
\hline \multirow{2}{*}{$\begin{array}{c}\text { Physico-chemical } \\
\text { factor }\end{array}$} & \multicolumn{2}{|c|}{ Site I } & \multicolumn{2}{|c|}{ Site II } & \multicolumn{2}{|c|}{ Site III } & \multicolumn{2}{|c|}{ Site IV } & \multicolumn{2}{|c|}{ Site V } \\
\hline & L.S & W & L.S & W & L.S & $\mathrm{W}$ & L.S & $\mathrm{W}$ & L.S & W \\
\hline $\begin{array}{l}\text { Light intensity } \\
(\times 100 \text { Lux })\end{array}$ & $678 \pm 3.5$ & $65 \pm 1.5$ & $665 \pm 5.5$ & $8 \pm 0.58$ & $217 \pm 2$ & $45 \pm 2$ & $285 \pm 1$ & $18 \pm 1.4$ & $415 \pm 0.58$ & $26 \pm 1$ \\
\hline Water temp. $\left({ }^{\circ} \mathrm{C}\right)$ & $30.3 \pm 0.2$ & $20.6 \pm 0.6$ & $29.8 \pm 0.2$ & $18.5 \pm 0.3$ & $29.4 \pm 0.15$ & $19.9 \pm 0.1$ & $29.8 \pm 0.1$ & $20.1 \pm 0.06$ & $29.8 \pm 0.1$ & $21.6 \pm 0.7$ \\
\hline $\mathrm{pH}$ & $7.6 \pm 0.02$ & $8 \pm 0.12$ & $7.2 \pm 0.23$ & $7.1 \pm 0.19$ & $7.5 \pm 0.06$ & $7.7 \pm 0.03$ & $7.6 \pm 0.05$ & $7.8 \pm 0.06$ & $7.5 \pm 0.05$ & $7.7 \pm 0.02$ \\
\hline $\begin{array}{l}\text { Electrical condu- } \\
\text { ctivity (ms/cm) }\end{array}$ & $0.7 \pm 0.03$ & $0.6 \pm 0.03$ & $0.6 \pm 0.02$ & $0.8 \pm 0.006$ & $0.5 \pm 0.03$ & $0.5 \pm 0.03$ & $0.6 \pm 0.05$ & $0.5 \pm 0.03$ & $0.5 \pm 0.03$ & $0.6 \pm 0.04$ \\
\hline $\begin{array}{l}\text { Dissolved oxygen } \\
(\mathrm{mg} / \mathrm{l})\end{array}$ & $4.87 \pm 0.01$ & $6.49 \pm 0.1$ & $4.87 \pm 0.006$ & $1.62 \pm 0.1$ & $3.24 \pm 0.006$ & $1.22 \pm 0.07$ & $2.43 \pm 0.02$ & $3.24 \pm 0.4$ & $4.05 \pm 0.01$ & $2.84 \pm 0.04$ \\
\hline $\begin{array}{l}\text { Inorganic } \\
\text { Phosphorous } \\
(\mathrm{mg} / \mathrm{l})\end{array}$ & $0.16 \pm 0.006$ & $0.08 \pm 0.003$ & $0.63 \pm 0.01$ & $0.40 \pm 0.02$ & $0.35 \pm 0.007$ & $1.15 \pm 0.02$ & $0.1 \pm 0.01$ & $0.07 \pm 0.006$ & $0.15 \pm 0.006$ & $0.85 \pm 0.02$ \\
\hline
\end{tabular}

for significance with Monte Carlo test (500 runs) using CANOCO software.

(j) Venn diagrams were generated by using the tool http://www.interactivenn.net to represent the unique and common microalgal taxa in different sites in late summer and winter seasons.

\section{Results and Discussion}

The microalgal components of phytoplankton community, collected from five ponds in the study area, were diverse. A total number of 23 taxa, identified up to genus, were recorded. These microalgae belong to 4 different classes, namely Cyanophyceae, Chlorophyceae, Bacillariophyceae 

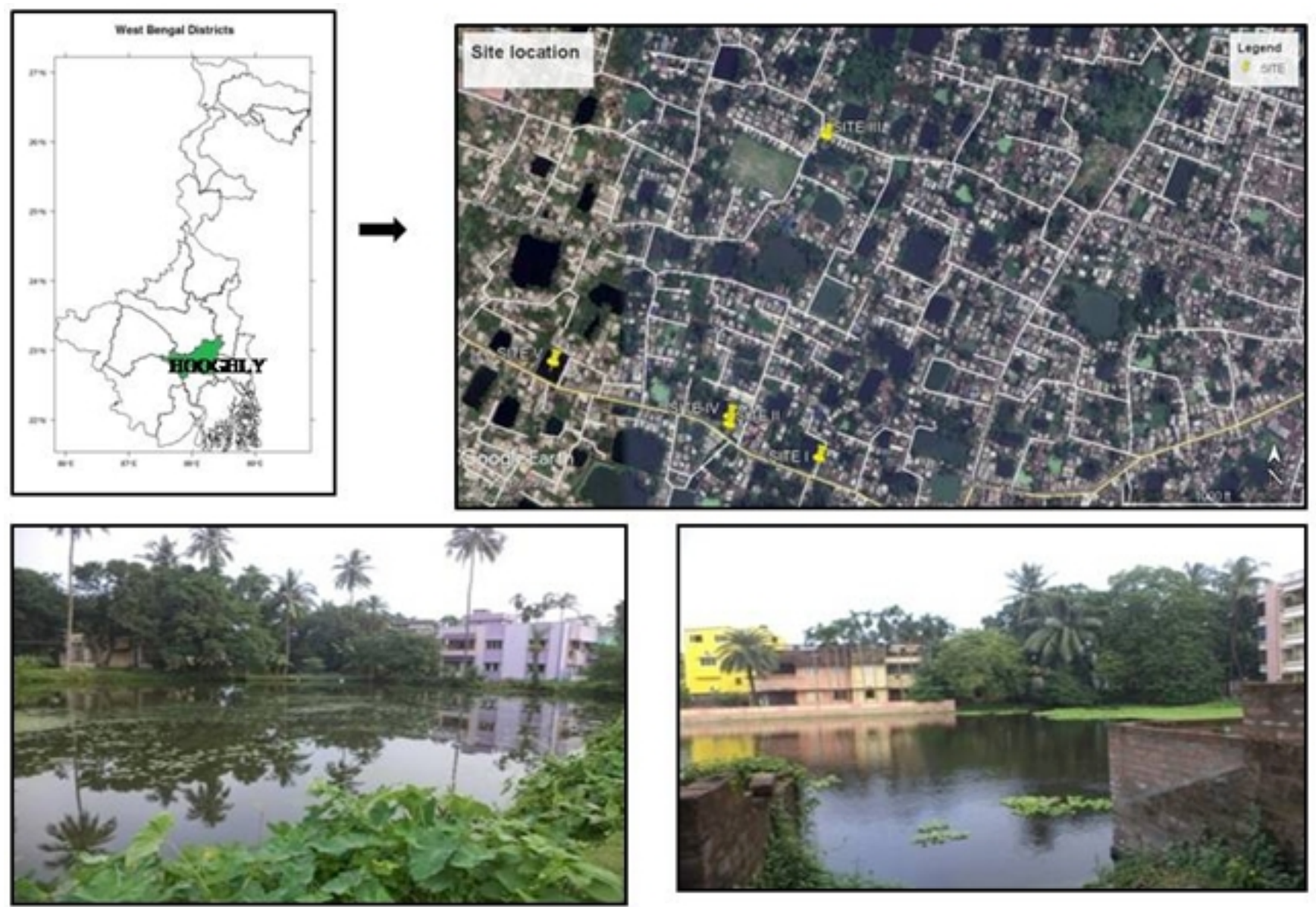

Photo plate 1. Location of study area and sampling sites

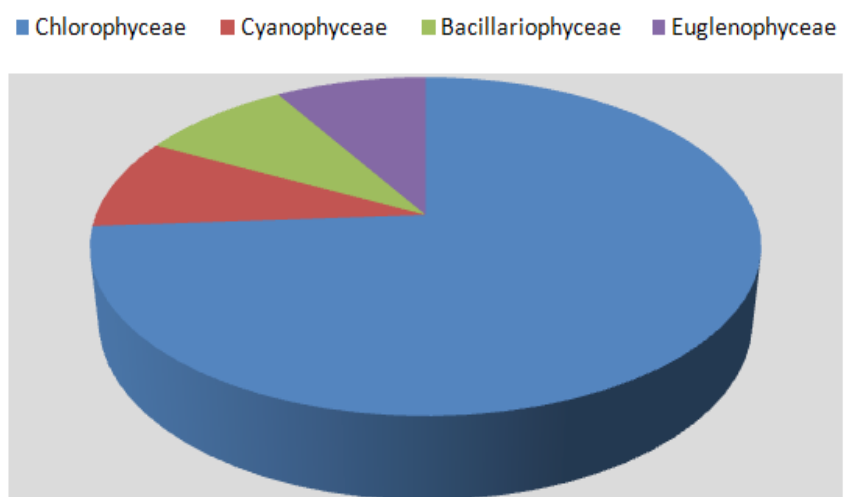

Fig. 1. Distribution percentage of microalgae group within study locations.

and Euglenophyceae (Table 3). Out of these 23 genera, 17 belong to the class Chlorophyceae followed by Cyanophyceae (2), Bacillariophyceae (2) and Euglenophyceae (2) (Table 2). Microphotographs of some of the organisms were given in Photo plate 2. Out of these genera occurrence of two genera belonging to Chlorophyceae is season specific - while Chodatella $\mathrm{sp}$. was recorded in late summer, Tetrallantos $\mathrm{sp}$. was recorded in winter season. Two Cyanophycean genera have been recorded namely Merismopedia sp. and Synechocystis sp. While Merismopedia sp. was recorded in both the seasons, Synechocystis sp. was recorded only in winter season. Two genera under

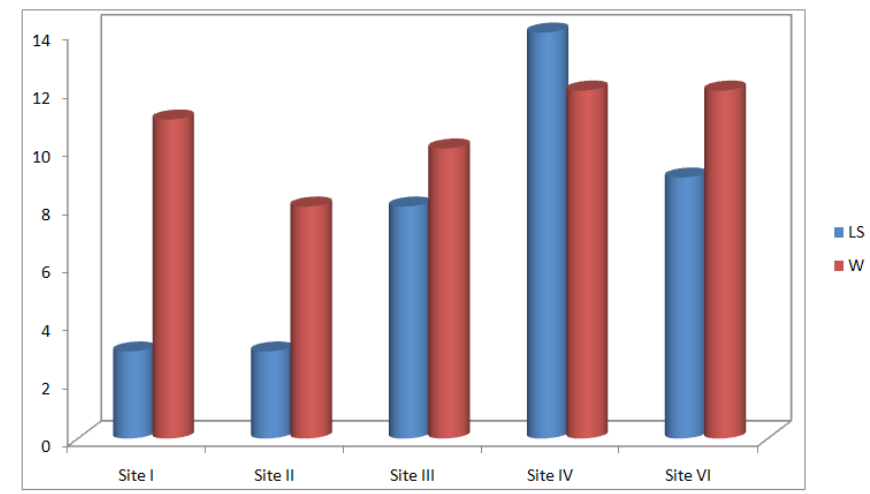

Fig. 2. Occurrence of microalgal genera in late summer (LS) and winter (W) in five sites.

Bacillariophyceae recorded were Navicula sp. and Pinnularia sp. Two genera of Euglenophyceae recorded were Euglena sp. and Phacus sp. According to distribution percentage of microalgal community component, occurrences of Chlorophyceae genera were maximum (74\%) followed by members of Cyanophyceae, Bacillariophyceae and Euglenophyceae $(8.69 \%$ in each) (Fig. 1). A similar result was obtained earlier in another study (29). Relative abundance of microalgal taxa was high in winter season in four sites except site IV. Diversity of taxa has been found to be much more in winter as compared to late summer except Site IV (Fig. 2). 

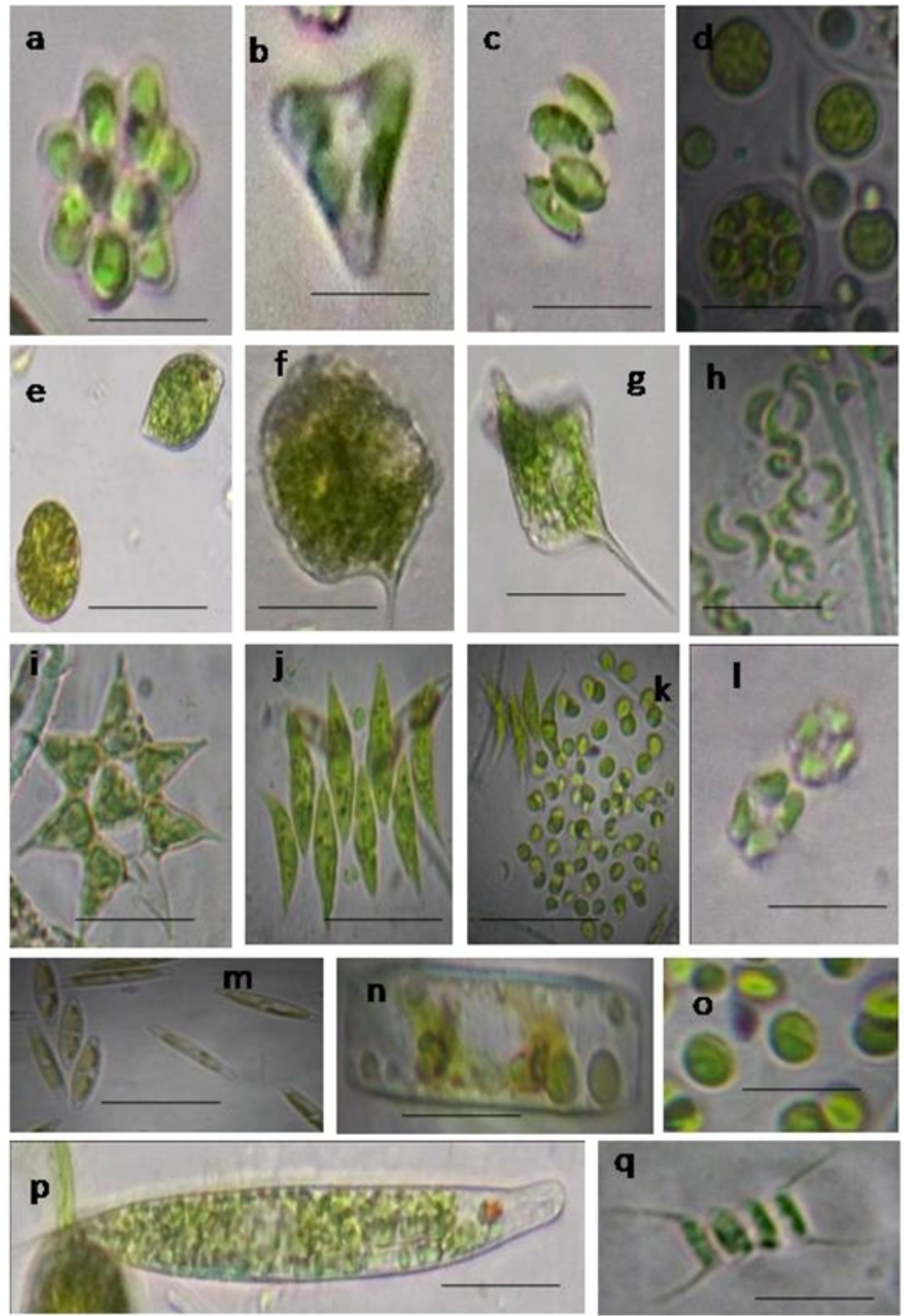

Photo plate 2. (20 $\mu \mathrm{m}$ scale) (a) Coelastrum sp., (b) Tetraedron sp., (c) Scenedesmus sp., (d) Chlorococcum sp., (e) Euglena sp., (f) Phacus sp., (g) Phacus sp., (h) Selenastrum sp., (i) Pediastrum sp., (j) Scenedesmus sp., (k) Scenedesmus sp., (l) Crucigenia sp., (m) Navicula sp., (n) Pinnularia sp., (o) Chlorella sp., (p) Euglena sp., (q) Scenedesmus sp.

Physico-chemical parameters were recorded both in winter and late summer. Table 3 shows value of physico-chemical parameters in all the sites and in both the seasons. There is significant variation with respect to light intensity and water temperature in these two seasons at all the sites. Though other parameters show very little variations, inorganic phosphorous has higher concentration $(1.15 \mathrm{mg} / \mathrm{l}$ and $0.85 \mathrm{mg} / \mathrm{l})$ in site III and site $\mathrm{V}$, electrical conductivity shows high value $(0.8 \mathrm{~ms} / \mathrm{cm})$ in site II except in few cases. In late summer, value of light intensity and water 

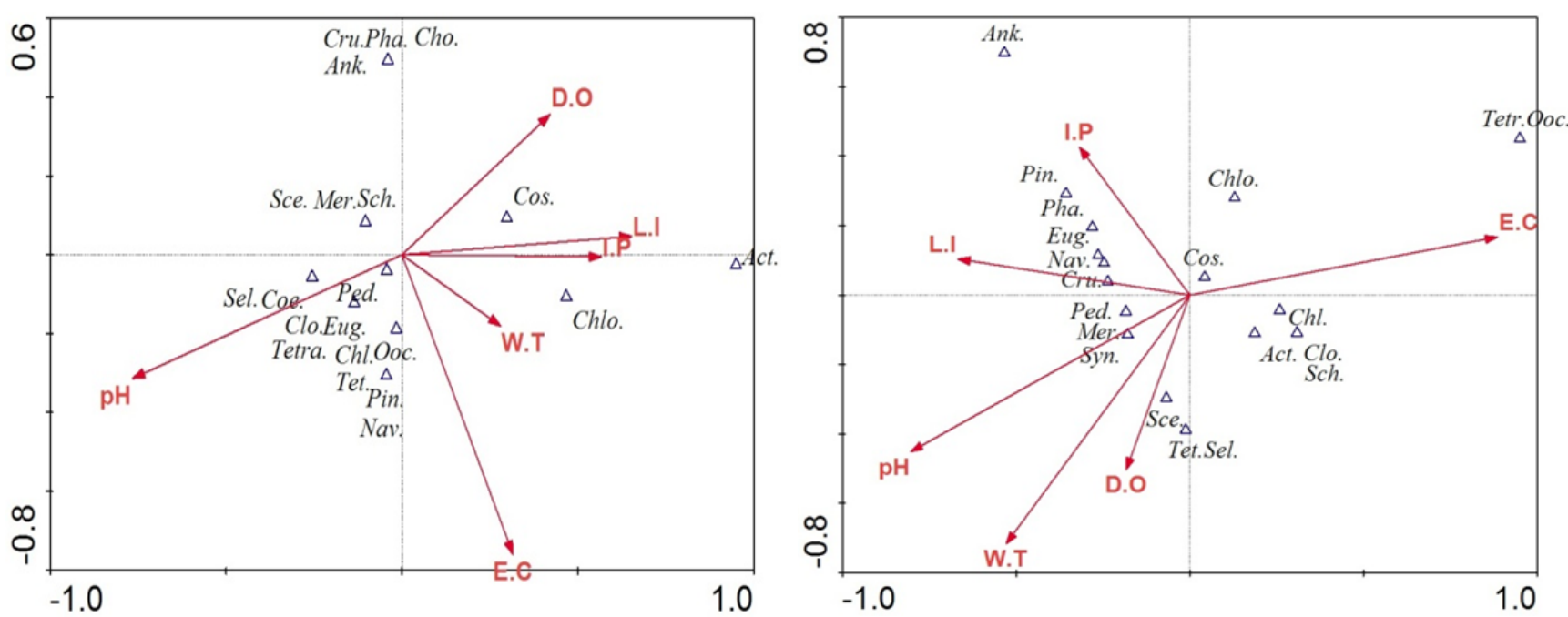

Fig. 3. CCA ordination biplot based on PCA (vide table 4) Fig. 4. CCA ordination biplot based on PCA (vide table 5) showing the relative position of species-environment showing the relative position of species-environment correlation between species occurrence and physico-chemical correlation between species occurrence and physico-chemical parameters in late summer season. parameters in winter season.

Table 4. CCA ordination score plot for late summer season based on first two principal components

\begin{tabular}{lllll}
\hline Axes & 1 & 2 & 3 & 4 \\
\hline Eigen values & 0.602 & 0.512 & 0.490 & 0.191 \\
\hline $\begin{array}{l}\text { Cumulative percentage of variance } \\
\text { explained by species }\end{array}$ & 33.5 & 62.1 & 89.4 & 100.0 \\
\hline
\end{tabular}

Table 5. CCA ordination score plot for winter season based on first two principal components

\begin{tabular}{lllll}
\hline Axes & 1 & 2 & 3 & 4 \\
\hline Eigen values & 0.396 & 0.238 & 0.197 & 0.090 \\
\hline $\begin{array}{l}\text { Cumulative percentage of variance } \\
\text { explained by species }\end{array}$ & 43.0 & 68.9 & 90.3 & 100.0 \\
\hline
\end{tabular}

temperature are higher than winter season. $\mathrm{pH}$ was more alkaline in winter season than late summer and winter except Site II.

Euglenophycean genera were present in Site III, Site IV and Site V in late summer and winter. In Site III both Euglenophycean genera, Euglena sp., Phacus sp., were present in winter season and also noticed that inorganic phosphorous concentration was high. Same result found in CCA analysis also. Euglenophycean genera plays a role as biological indicator of organic pollution (31). In Site I Synechocystis sp. was present in winter season and $\mathrm{pH}$ (8) was found to be high when compared to other sites. In Site II Tetrallantos sp. was present in winter season and the physico-chemical parameter, electrical conductivity value (0.8) was found to be high than other sites. Pediastrum sp. was found in high $\mathrm{pH}(7.5-8)$ sites I, sites III, site IV sites V and the same result was observed in CCA analysis. Chlorococcum sp., was present in winter season except in Site IV. Tetraedron sp., was present in both the seasons in Site IV.

Canonical correspondence analysis showed correlation between species (here species represents taxa) occurrence and environmental parameters both at late summer and winter. In the graph (Fig. 3 and 4) ' $\Delta$ ' represents occurrence of species and ' $\rightarrow$ ' represents environmental variables. The result from the ordination diagram indicates that the relative weight, as denoted by extra fit values, for the environmental variables indicates a narrow range of variation $(0.3359$ 0.5126 ) with a $p$ - value of 0.1160 in late summer sampling (Fig. 3) and (0.1612-0.3467) with a pvalue of 0.0580 in winter season, (Fig. 4) respectively. Therefore, result for winter season is statistically more reliable. The eigenvalues for corresponding axes indicate that the first axis is contributing the most in explaining the species environment relationship (0.602) in case of late summer and (0.396) in winter. The second axis is contributing more than remaining two axes in both seasons. In late summer, Axis 1 has the strongest positive correlation with light intensity and weakest positive correlation with water temperature. Axis 2 has the strongest positive correlation with dissolved oxygen and weakest positive correlation with light intensity. Axis 1 shows negative correlation with water $\mathrm{pH}$. Axis 2 shows negative correlation with water 


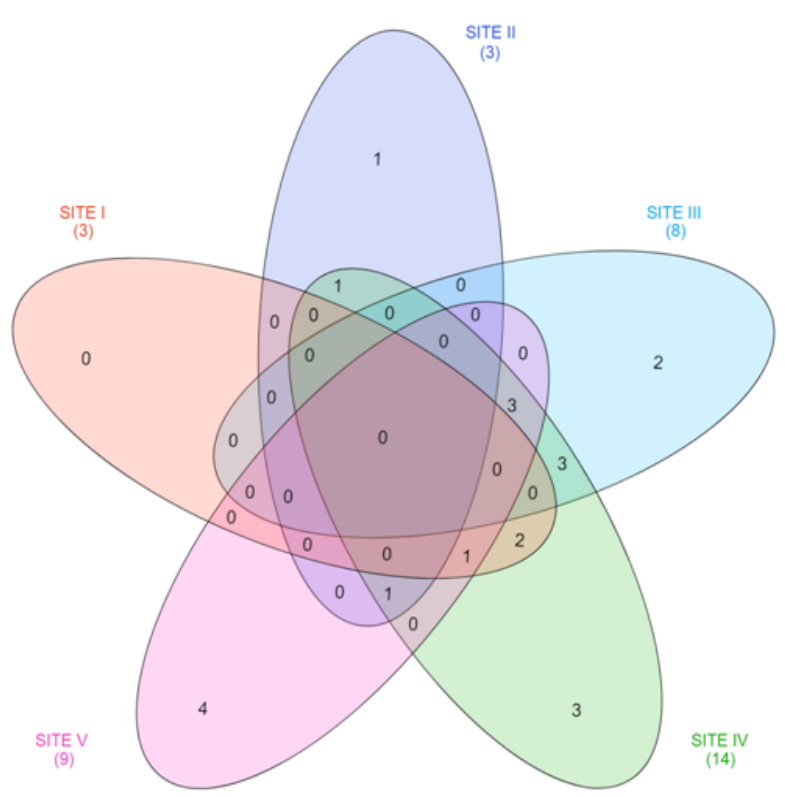

Fig. 5. Graphical presentation of all the microalgal taxa from the five study sites (Site I, II, III, IV \& V) in late summer based on commonality of occurrence.

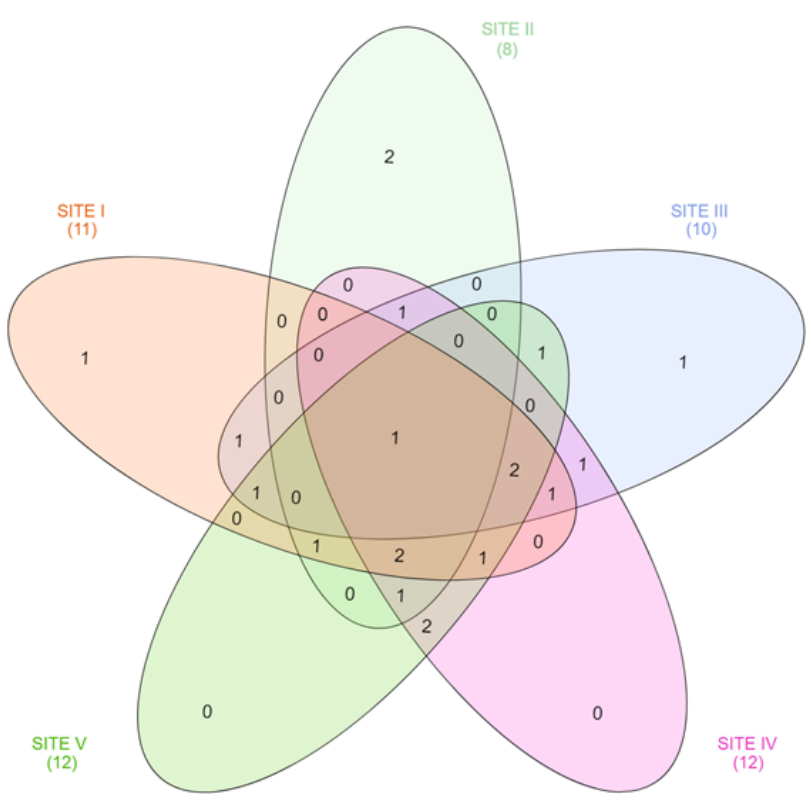

Fig. 6. Graphical presentation of all the microalgal taxa from the five study sites (Site I, II, III, IV \& V) in winter based on commonality of occurrence.

Table 6. Diversity indices of microalgal class component in five sites under that investigation (L.S: Late summer, W: Winter)

\begin{tabular}{|c|c|c|c|c|c|c|c|c|c|c|}
\hline \multirow{2}{*}{ Diversity indices } & \multicolumn{2}{|c|}{ Site I } & \multicolumn{2}{|c|}{ Site II } & \multicolumn{2}{|c|}{ Site III } & \multicolumn{2}{|c|}{ Site IV } & \multicolumn{2}{|c|}{ Site V } \\
\hline & L.S & $\mathrm{W}$ & L.S & $\mathrm{W}$ & L.S & $\mathrm{W}$ & L.S & $\mathrm{W}$ & L.S & $\mathrm{W}$ \\
\hline Taxa (class level) & 2 & 3 & 1 & 1 & 3 & 4 & 4 & 4 & 3 & 3 \\
\hline $\begin{array}{l}\text { Shannon-Wiener diversity index } \\
{\left[H^{\prime}\left(\log _{\mathrm{e}}\right)\right]}\end{array}$ & 0.6365 & 0.9075 & 0 & 0 & 0.7356 & 1.221 & 0.8953 & 0.837 & 0.6837 & 0.5661 \\
\hline $\begin{array}{l}\text { Simpson's dominance index } \\
\left(D_{S I P M}\right)\end{array}$ & 0.4444 & 0.5289 & 0 & 0 & 0.4063 & 0.66 & 0.4592 & 0.4167 & 0.3704 & 0.2917 \\
\hline Pielou's evenness index ( $/$ /) & 0.9449 & 0.8261 & 1 & 1 & 0.6956 & 0.8473 & 0.612 & 0.5774 & 0.6604 & 0.5871 \\
\hline Margalef's richness index $\left(D_{\text {MARG }}\right)$ & 0.9102 & 0.8341 & 0 & 0 & 0.9618 & 1.303 & 1.137 & 1.207 & 0.9102 & 0.8049 \\
\hline
\end{tabular}

temperature, water $\mathrm{pH}$ and electrical conductivity, whereas, in winter Axis 1 has the strongest positive correlation with electrical conductivity. Axis 2 has the strongest positive correlation with inorganic phosphorous and weakest positive correlation with light intensity. Axis 1 shows negative correlation with light intensity, water temperature, water $\mathrm{pH}$, dissolved oxygen, inorganic phosphorous. Axis 2 shows negative correlation with water temperature, water $\mathrm{pH}$, dissolved oxygen. All the four eigenvalues reported above are canonical and correspond to axes that are constrained by the environmental variables in both seasons. In late summer (Fig. 3), Cosmarium sp. and Actinochloris sp. showed affinity with dissolved oxygen, inorganic phosphate and light intensity in axis 1. Schroederia sp., Scenedesmus sp., Merismopedia sp., Crucigenia sp., Phacus sp., Chodatella sp., Ankistrodesmus sp. are positive correlated with dissolved oxygen. In axis 2 the species have strong negative correlation with electrical conductivity. Chlorococcum sp., Tetraedron sp., Oocystis sp., Pinnularia sp., Navicula sp. are aline with electrical conductivity.
Pediastrum sp., Euglena sp., Closterium sp., Tetrastrum sp., Selenastrum sp., Coelastrum sp. are aligned with water $\mathrm{pH}$. Water temperature has no significant role in late summer. In winter season (Fig. 4), Chlorococcum sp., Closterium sp., Schroederia sp., are aligned with electrical conductivity in strong relationship. Phacus sp., Euglena sp., Pinnularia sp., Navicula sp. are aligned with inorganic phosphorous. Crucigenia sp., Merismopedia sp., Pediastrum sp. are aligned with water $\mathrm{pH}$ and light intensity. Synechocystis $\mathrm{sp}$. occurs with increasing water temperature. A similar result was found in another study (19). Table 4 and 5 represent the CCA ordination score plot for late summer and winter seasons based on first two principal components.

It is observed from Table 6 that representatives of all the four classes (Chlorophyceae, Cyanophyceae, Bacillariophyceae, Euglenophyceae) were found in both the season in Site IV and in winter season in Site III. Representative of only one class (Chlorophyceae) was found in Site II in both the seasons. Shannon- 
Wiener diversity index was highest at winter season of Site III (1.221). It is interesting to note here that Margalef's richness index is also highest here (1.303) and Pielou's evenness index is low here. In Site II, Shannon- Wiener diversity index is 0 . Simpson's dominance index value is also 0 as there is representation of only one class was present there. Naturally Pielous's evenness index value is 1 and Margalef's richness index is 0 (29).

In late summer season, unique microalgal taxa observed are as follows (Fig. 5): maximum number was observed in Site V (Crucigenia sp., Chodatella sp., Ankistrodesmus sp., Phacus sp.), one in Site II (Actinochloris sp.), two in Site III (Selenastrum sp. and Coelastrum sp.), three in Site IV (Chlorococcum sp., Tetraedron sp., Oocystis sp.).

Following common microalgal taxa were observed in different sites (Fig. 5): one in Site II and Site IV (Chlorella sp.), three in Site III, IV and V (Scenedesmus sp., Schroederia sp., Merismopedia sp.). Another three found in Site III and IV (Tetrastrum sp., Closterium sp., Euglena sp.), two in Site I and IV (Navicula sp., Pinnularia sp.), one in Site I, IV and V (Pediastrum sp.) and another one in Site II, IV and V (Cosmarium sp.).

In winter season, unique microalgal taxa observed are as follows (Fig. 6): one in Site I (Synechocystis sp.) and Site III (Ankistrodesmus sp.), two in Site II (Tetrallantos sp., Oocystis sp.).

Following common microalgal taxa were recorded in different sites (Fig. 6): one in the following sites representing with different taxa: Site II, III and IV (Chlorella sp.), Site III and V (Euglena sp.), Site III and IV (Phacus sp.), Site I, III and IV (Navicula sp.), Site I, IV and V (Scenedesmus sp.), Site II, IV and V (Closterium sp.), Site I, II and V (Chlorococcum sp.), Site I, III and V (Crucigenia sp.), Site I and III (Pinnularia sp.), SITE I -V (Cosmarium sp.). Two common taxa were noted in Site I, III, IV and V (Pediastrum sp. Merismopedia sp.), Site IV and V (Selenastrum sp.,Tetraedron sp.), Site I, II, IV and V (Schroederia sp., Actinochloris sp.).

Moreover, these ponds are the sink of all domestic pollution because of through open drainage system from which brings the domestic waste of nearby settlements enters to the specific site. Shannon's diversity values depicted minor fluctuations with respective sites because there was no remarkable difference in the number of taxa composing dominant species at different sites. It has been observed $(30,31)$ that incase of polluted areas, there was a decrease in biomass of the microalgae in phytoplankton associated with increase in species diversity. Diversity index is a good index for assessing and ranking the water quality. Analysis of diversity of microalgal flora of the lake leads to conclusion that the mean values did not differ from each other remarkably at the stations in different seasons studied, which can be directly related to the eutrophication process of aquatic system (32). Wetland ecosystems are the primary shelter for aquatic biodiversity including aquatic flora, fauna and other microorganisms. Phytoplankton is one of the important components of aquatic ecosystems (4). Fresh water ponds play an important role in the social ecology of the region in which they are located. Phytoplankton ecology plays an important role for indicating the eutrophication (33) as well as water quality and further way forward towards ecosystem management.

Major outcome: (i) The ponds located very near to the human residential complexes show a rich microalgal flora dominated by Chlorophycean members belonging to the order Chlorococcales and desmids (Desmidales). (ii) The microalgal genera are more abundant in winter season than in late summer. (iii) Two genera have been found to be season specific Synechocystis sp., Tetrallantos sp.

\section{Acknowledgements}

This study was supported by a Grant from the Department of Biotechnology, Government of West Bengal (DBT WB) to Dr, Manojit Debnath. Papiya Halder is thankful to DBT WB and UGC, New Delhi for research fellowship. Authors are acknowledging Dr. S. Bhattacharya, Dr. S. I. Maiti and Dr. S. N. Ojha for helping in statistical analysis. Papiya Halder is also thankful to the Head, P.G. Department of Botany, Hooghly Mohsin College for partial laboratory facilities and Dr. M. L. Ghosh for encouragement.

\section{Competing Interests}

The authors have no conflict of interests.

\section{Authors' contribution}

All authors contributed equally to carry out the research and prepare article.

\section{References}

1. Dawes CJ. Marine Botany. 2nd Ed. John wiley and sons InC., New York; 1998.

2. Jyothi K, Narasimha Rao GM. Seasonal Distribution of Phytoplankton in Riwada Reservoir, Visakhapatnam, Andhra Pradesh, India. Notulae Scientica Biologica 2013; 5: 290-295. https://doi.org/10.15835/nsb539082

3. Shiddamallayya N, Pratima M. Seasonal Changes in Phytoplankton Community in Papnash Pond, Bidar, Karnataka Along With Physico-Chemical Characteristics of Water. Journal of Advances in Developmental Research 2011; 2:186-190.

4. Katari B, Nautiyal S, YD, Khan I, Rajanna L. A Preliminary Study on Phytoplankton in Fresh Water-Lake of Gogi, Yadgir District, Karnataka. International Journal of Innovative Research in Science, Engineering and Technology 2015; 4. http:// doi.org/10.15680/IJIRSET.2015.0404031 
5. Kanagasabapathi V, Rajan MK. A Preliminary survey of Plankton in Irrukkangudi Reservoir, Virudhunagar District, T.N. India Journal of Phytology 2010; 2: 63-72.

6. Ravishankar HG, Murthy GP, Lokesh S, Hosmani SP. Diversity of Fresh water algae in two Lakes of Tumkur, Karnataka State, India. 13th Wuhan Conference 2009; 1-17.

7. Shankar H, Mruthunjaya TB. Distribution of Phytoplankton in Lakes of Tirumalkudal Narasipura of Mysore District. Journal of Reasearch in Science \& Technology 2012; 1: 28-32.

8. Ramesha MM, Sophia S. Species Composition and Diversity of Plankton in the River Seeta at Seetanadi, the Western Ghats, India. Advanced Bio Tech 2013; 12: $20-27$.

9. Komala HP, Nanjundaswamy L, Devi Prasad AG. An assessment of Plankton diversity and abundance of Arkavathi River with reference to pollution. Advances in Applied Science Research 2013; 4: 320324.

10. Suresh B, Manjappa S, Puttaiah ET. Dynamics of phytoplankton succession in Tungabhadra River near Harihar, Karnataka (India). Journal of Microbiology and Antimicrobials 2013; 5: 65-71. https://doi.org/10.5897/JMA10.031

11. Venkateshwarlu M, Shahnawaz A, Honneshappa K. A study on plankton dynamics of two wetland systems in Shimoga District, Karnataka (India). Current Biotica 2011; 4: 461-468.

12. Singh PR, Balasingh RGS. Limnological Studies of Kodaikanal Lake (Dindugal District), in Special Reference to Phytoplankton Diversity. Indian Journal of Fundamental and Applied Life Sciences 2011; 1: 112-118.

13. Manickam N, Bhavan PS, Vijayan P, Sumathi G. Phytoplankton Species Diversity in the Parambikulam-Aliyar Irrigational Canals (Tamil $\mathrm{Nadu}$, India). International Journal of Pharma and Bio Sciences 2012; 3: 289 - 300.

14. Senthilkumar R, Sivakumar K. Studies on phytoplankton diversity in response to abiotic factors in Veeranam lake in the Cuddalore district of Tamil Nadu. Journal of Environmental Biology 2008; 29: 747-752.

15. Suresh B, Manjappa S, Puttaiah ET. Seasonal Variation of Hyto Lankton in Tungabhadra River near Harihar-Karnatak. Research Journal of Biological Science 2011; 6: 65-68. https://doi.org/10.3923/rjbsci.2011.65.68

16. Sedamkar EB, Jayashree T. Limnological Studies on Kadapur Lake with Specieal Reference to Phytoplanktons. World Journal of Science and Technology 2011; 1: 22-25.

17. Gayathri N, Rajashekhar M, Fatima K, Vijaykunar K, Ratandeep Baburrao M. Hydrochemistry and Plankton Diversity of Tungabhadra Reservoir Bellary District, Karnataka. International Journal of Zoology Research 2011; 1: 1-7.

18. Divya KS, Murthy SM, Puttaiah ET. A Comparative Study of the Growth of Phytoplanktons in surface water samples and in the formation of Algal blooms. International Journal of Innovative Research in Science, Engineering and Technology 2013; 2: 27362747.

19. Çelekli A., Öztürk B, Kapı M. Relationship between phytoplankton composition and environmental variables in an artificial pond. Algal Research 2014; 5: 37-41. http://dx.doi.org/10.1016/j.algal.2014.05.002

20. Çelekli A, Külköylüoğlu O. On the relationship between ecology and phytoplankton composition in a karstic spring (Çepni Bolu). Ecol. Indic. 2007; 7: 497-503.

https://doi.org/10.1016/j.ecolind.2006.02.006

21. Huovinen PS, Brett MT, Goldman CR. Temporal and vertical dynamics of phytoplankton net growth in Castle Lake, California. J. Plankton Res. 1999; 21: 373-385. https://doi.org/10.1093/plankt/21.2.373

22. Garibaldi L, Anzani A, Marieni A. Studies on the phytoplankton of the deep subalpine Lake Ise. J. Limnol. 2003; 62: 177-189. https://doi.org/10.4081/jlimnol.2003.177

23. Reynolds CS. The Ecology of Phytoplankton, Cambridge University Press, Cambridge. 2006. https://doi.org/10.1017/CBO9780511542145

24. Reynolds CS, Huszar V, Kruk C.Towards a functional classification of the freshwater phytoplankton, review. J. Plankton Res. 2002; 24 (5): 417-428. https://doi.org/10.1093/plankt/24.5.417

25. Philipose MT. Chlorococcales. Indian Council of Agricultural Research, New Delhi; 1967.

26. Sarode PT, Kamat ND. Freshwater Diatoms of Maharashtra. Institute of Science Aurangabad (Maharashtra) Saikripa Prakasan Aurangabad; 1984.

27. Graham LE, Graham JM, Wilcox LW. Algae, $2^{\text {nd }}$ edn. Pearson Benjamin Cummings. 2009.

28. Das D, Keshri JP. Desmids of Eastern Himalaya. Bibliotheca. J. Cramer in Borntraeger Science Publishers. Stuttgart; 2016. 119.

29. Ajayan AP, KG AK. Micro algal diversity of the lake inside the government zoological garden, Thiruvanathapuram, Kerala India. International journal of Environmental Sciences 2015; 6 (3): 330337. http://doi.org/10.6088/ijes.6037

30. Mir AR, Wanganeo A,Yousuf AR, Wananeo R. Diversity index of algal flora in Wular lake in Kashmir. Nature Environment and Pollution Technology 2010; 9(2): 293-298.

31. Eloranta P. Species diversity in the phytoplankton of some Finnish lakes. Ann. Bot. Fenn. 1976; 13: 42-48.

32. Effendi H, Kawaroe M, Lestari DF, Mursalin, Permadi T. Distribution of phytoplankton diversity and abundance in Mahakam Delta, East Kalimantan. Procedia Environmental Sciences 2016; 33: 496 504. http://doi.org/10.1016/j.proenv.2016.03.102

33. Giripunje MD, Fulke AB, Khairnar K, Meshram PU, Paunikar WN. A Review of Phytoplankton Ecology in freshwater lakes of India. Lakes, reservoirs and ponds 2013; 7(2): 127-141. 